EESTI NSV TEADUSTE AKADEEMIA TOIMETISED. 19. KÖIDE KEEMIA * GEOLOOGIA. 1970, Nr. 2

ИЗВЕСТИЯ АКАДЕМИИ НАУК ЭСТОНСКОИ ССР. ТОМ 19 ХИМИя * ГЕОЛОГИЯ. 1970, № 2

\title{
РАВНОВЕСИЕ ЖИДКОСТЬ - ПАР В СИСТЕМАХ ГЕКСЕН-1 - ВОДА, ГЕКСЕН-1 - УКСУСНАЯ КИСЛОТА, ГЕПТЕН-1 - ВОДА
}

Равновесие между жидкостью и паром в расслаивающихся бинарных системах гексен-1 - вода, гексен-1 - уксусная кислота, гептен-1 - вода исследовалось в изотермических условиях в микроприборе, сконсгруированном Вихтерле и Хала $\left.{ }^{1}\right]$ (прн температуре $55^{\circ} \mathrm{C}$ для систем, содержащих гексєн-1, и при $75^{\circ}$ для системы гептен-1 вода). Цель работы - отработка методики определения составов расслаивающегося раствора и равновесного с ним пара, а также проверка возможности расчета давления трехфазного равновесия по полученным данным о составах сосуществующих фаз.

\section{Экспериментальная часть}

Р е а к и вы, использованные в работе, имели следующие характеристики:

T. кип., ${ }^{\circ} \mathrm{C}$

$$
63,5
$$

93,6

100,0

118,1
$n_{D}^{20}$

1,3879

1,3996

1,3330

1,3720 $d_{4}^{20}$

0,6731

0,6973

вода

уксусная кислота

Ан ализ раствора и пара проводился в приборе УХ-1 при температуре $95^{\circ}$ на трехметровой колонке с наполнителем из полиэтиленгликоля 4000 на тефлоне. Газ-носитель - водород, скорость потока газа $100 \mathrm{M} \Omega / \mathrm{MLH}$.

Қомпоненты раствора вводились в микроприбор шприцем. После установления равновесия, отбора пара и его анализа в ячейку прибора добавлялся гомогенизатор; однородная смесь извлекалась шприцем и анализировалась. Для введения поправки приготовлялся по весу контрольный раствор (с гомогенизатором). Погрешность определения составов $\pm 0,5 \%$.

\section{Экспериментальные данные}

Результаты определения составов сосуществующих фаз представлены в табл. 1 -3. Для всех трех систем исследованная концентрационная область $(0,1-0,9$ мол. \%) отвечает трехфазному равновесию жидкость-жидкость-пар. В таблицах наряду с брутто-составом жидкости $\left(x_{i}^{(1)}\right)$ и составом пара $\left(x_{i}^{(2)}\right.$ равно среднему значению из 8-9 опре- 
таблица 1

Равновесие жидкость - пар

в системе гексен-1 (1) - вода (2) при $55^{\circ}$

\begin{tabular}{|c|c|c|c|c|c|c|}
\hline \multirow[t]{2}{*}{$x_{1}^{(1)}$} & \multirow[t]{2}{*}{$x_{1}^{(2)}$} & \multirow[t]{2}{*}{$\alpha_{12}$} & \multirow{2}{*}{$\lg \frac{\gamma_{1}}{\gamma_{2}}$ эксп } & \multirow{2}{*}{$\begin{array}{l}\lg \frac{\gamma_{1}}{\gamma_{2}} \text { расч. } \\
b=1,1055 \\
c=0,0166 \\
d=0,2922\end{array}$} & \multicolumn{2}{|c|}{$\begin{array}{l}\text { Расчетные значения } \\
\text { давления, мм рт. ст. }\end{array}$} \\
\hline & & & & & $P_{I}$ & $P_{\text {II }}$ \\
\hline \multirow{10}{*}{$\begin{array}{l}0,100 \\
0,200 \\
0,300 \\
0,400 \\
0,500 \\
0,600 \\
0,700 \\
0,800 \\
0,900\end{array}$} & 0,837 & 46,218 & 0,9765 & 0,9423 & 640 & 685 \\
\hline & , & 20,540 & 0,6244 & 0,6135 & 666 & 677 \\
\hline & $"$ & 11,980 & 0,3903 & 0,3670 & 655 & 672 \\
\hline & $"$ & 7,699 & 0,1981 & 0,1746 & 650 & 667 \\
\hline & " & 5,135 & 0,0224 & 0,0083 & 660 & 663 \\
\hline & " & 3,423 & $-0,1539$ & $-0,1600$ & 663 & 667 \\
\hline & , & 2,201 & $-0,3457$ & $-0,3584$ & 662 & 672 \\
\hline & $"$ & 1,284 & $-0,5797$ & $-0,6149$ & 659 & 673 \\
\hline & $"$ & 0,571 & $-0,9318$ & $-0,9575$ & 658 & 679 \\
\hline & & & & & $\bar{P}_{\mathrm{I}}=657$ & $\bar{P}_{\text {II }}=673$ \\
\hline
\end{tabular}

Равновесие жидкость - пар

таблица 2 в системе гептен-1(1) - вода (2) при $75^{\circ}$

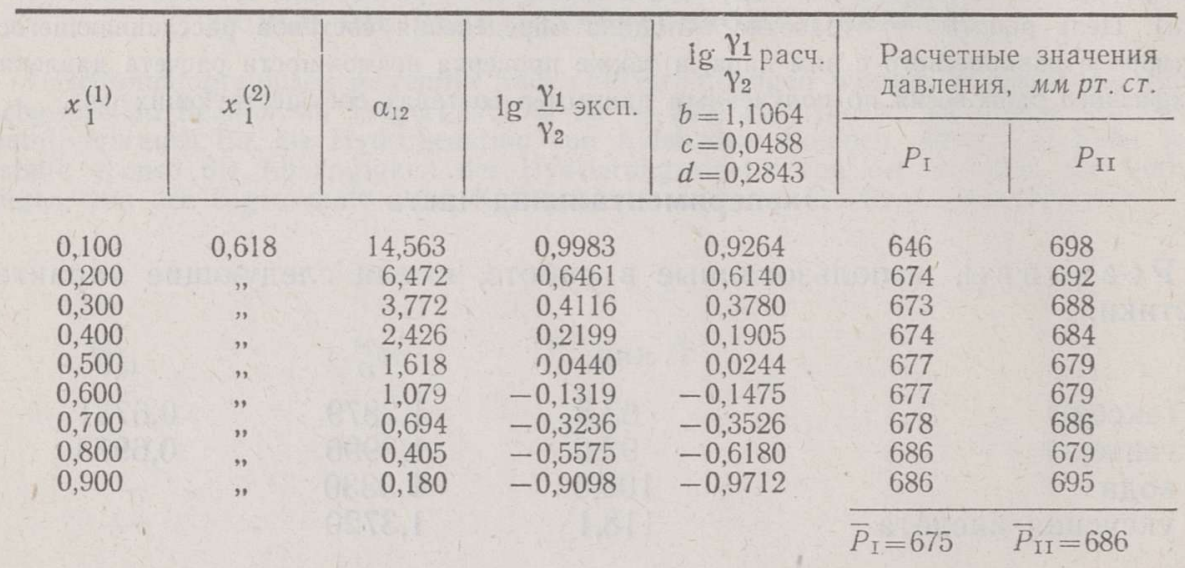

Таблица 3

Равновесие жидкость - пар

в системе гексен-1 (1) - уксусная кислота (2) при $55^{\circ}$

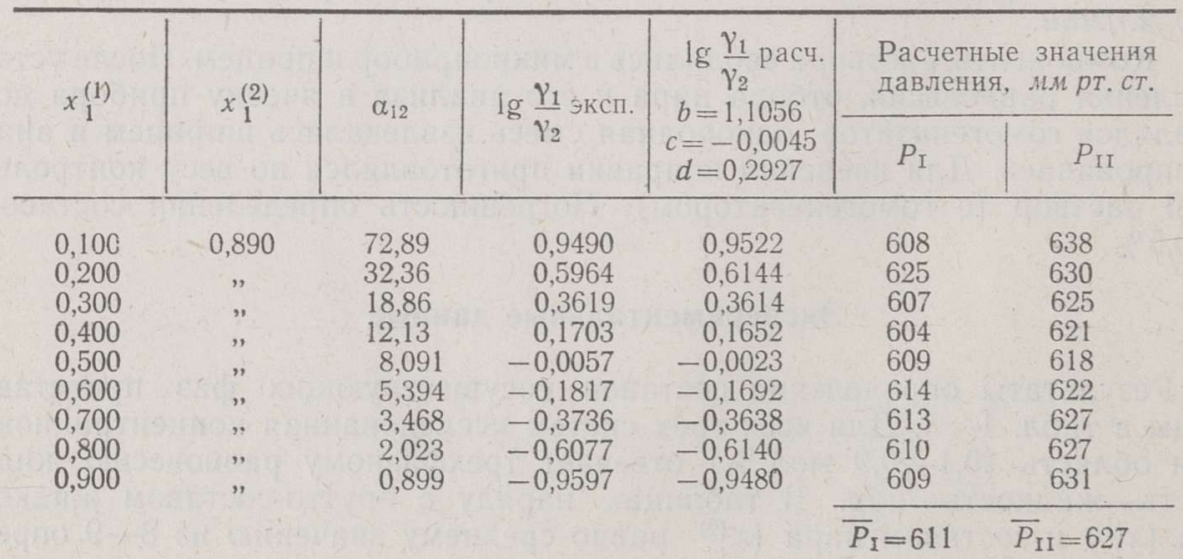


делений) приводится величина относительной летучести $\left(\alpha_{12}\right)$, рассчитанная для валового состава жидкости, а также значения $\lg \frac{\gamma_{1}}{\gamma_{2}} \quad$ эксп.= $=\lg \left[\alpha_{12} \cdot \frac{p_{2}^{0}}{p_{1}^{0}}\right]^{*}$ (где $\gamma_{i}-$ коэффициент активности компонента).

Корреляция экспериментальных данных проведена с помощью уравнения Редлиха-Кистера IV порядка [5], константы для которого определялись методом, описанным ранее [6, 7]. Расчетные значения логарифма отношения коэффициентов активности сравниваются в таблицах с величинами $\lg \frac{\gamma_{1}}{\gamma_{2}}$ эксп.

Величина общего давления $(P)$ рассчитывалась из соотношения

$$
P=p_{1}^{0} \cdot x_{1}^{(1)} \cdot \gamma_{1}+p_{2}^{0} \cdot x_{2}^{(1)} \cdot \gamma_{2} .
$$
бом:

Згачения коэффициентов активности определялись двояким спосо-

1) по уравнению Редлиха-Кистера IV порядка (величина давления, рассчитанная на основе этих значений $\gamma_{i}$, обозначена в таблицах $P_{1}$ );

2) из графика зависимости $\lg \frac{\gamma_{1}}{\gamma_{2}}$ эксп. $=f\left(x_{1}^{(1)}\right)$, в котором значения $\lg \gamma_{i}$ отвечают площадям, ограниченным кривой $\lg \frac{\gamma_{1}}{\gamma_{2}}=f\left(x_{1}^{(1)}\right)$ и соответственно ординатами $x_{i}=1$ и $x_{i}=0$ [8] (этим значениям $\gamma_{i}$ отвечает величина $P_{\mathrm{II}}$ ). Величина площадей определялась методом Симпсона (методом парабол).

Для проверки соответствия результатов расчета, в основу которого положены лишь данные о равновесных составах, экспериментально определенному значению давления сравнивались расчетные и экспериментальные данные для систем вода (1) - бутилацетат (2) [9] и пропилацетат (1) - вода (2) [10]. Результаты сравнения приводятся в табл. 4

Результаты расчета

общего давления при $44,6^{\circ}$ для системы вода (1) - бутилацетат (2)

\begin{tabular}{|c|c|c|c|c|c|c|}
\hline \multirow{2}{*}{$x_{1}^{(1)}$} & \multirow{2}{*}{$x_{1}^{(2)}$} & \multirow[t]{2}{*}{$\alpha_{12}$} & \multirow{2}{*}{$\lg \frac{\gamma_{1}}{\gamma_{2}}$ эксп } & \multirow{2}{*}{$\begin{array}{l}\lg \frac{\gamma_{1}}{\gamma_{2}} \text { расч. } \\
b=1,1059 \\
c=0,0150 \\
d=0,2929\end{array}$} & \multicolumn{2}{|c|}{$\begin{array}{l}\text { Расчетные значения } \\
\text { давления, мм рт.ст. }\end{array}$} \\
\hline & & & & & $P_{\mathrm{I}}$ & $P_{\text {II }}$ \\
\hline 0,100 & 0,700 & 21,018 & 0,9748 & 0,9434 & 95 & 100 \\
\hline 0,200 & , & 9,332 & 0,6222 & 0,6137 & 98 & 100 \\
\hline 0,300 & $"$ & 5,438 & 0,3878 & 0,3666 & 96 & 99 \\
\hline 0,400 & , & 3,498 & 0,1962 & 0,1739 & 98 & 98 \\
\hline 0,500 & " & 2,333 & 0,0203 & 0,0075 & 97 & 97 \\
\hline 0,600 & ", & 1,555 & $-0,1560$ & $-0,1607$ & 97 & 98 \\
\hline 0,700 & $"$ & 1,000 & $-0,3478$ & $-0,3588$ & 97 & 98 \\
\hline 0,800 & $n$ & 0,583 & $-0,5821$ & $-0,6149$ & 97 & 101 \\
\hline 0,900 & $"$ & 0,259 & $-0,9344$ & $-0,9572$ & 97 & 99 \\
\hline & & & & әксп. $=99,6$ & $\overline{P_{I}}=97$ & $\bar{P}_{I I}=99$ \\
\hline
\end{tabular}

* Значения давлений паров компонентов $\left(p_{i}^{0}\right)$ заимствованы из $\left[{ }^{2-4}\right]$. 


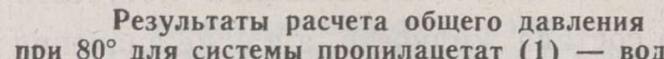

(2)

\begin{tabular}{|c|c|c|c|c|c|c|}
\hline \multirow{2}{*}{$x_{1}^{(1)}$} & \multirow{2}{*}{$x_{1}^{(2)}$} & \multirow{2}{*}{$\alpha_{12}$} & \multirow{2}{*}{$\lg \frac{\gamma_{1}}{\gamma_{2}}$ эरсп } & \multirow{2}{*}{$\begin{array}{c}\lg \frac{\gamma_{1}}{\gamma_{2}} \text { расч. } \\
b=1,0481 \\
c=-0,0927 \\
d=0,1765\end{array}$} & \multicolumn{2}{|c|}{$\begin{array}{l}\text { Расчетные значения } \\
\text { давления, } м м \text { рт. ст. }\end{array}$} \\
\hline & & & & & $P_{I}$ & $P_{\text {II }}$ \\
\hline \multirow{9}{*}{$\begin{array}{l}0,100 \\
0,200 \\
0,300 \\
0,400 \\
0,500 \\
0,600 \\
0,700 \\
0,817\end{array}$} & \multirow{9}{*}{$\begin{array}{c}0,486 \\
" \\
" \\
" \\
" \\
" \\
" \\
"\end{array}$} & \multirow{9}{*}{$\begin{array}{l}8,523 \\
3,784 \\
2,205 \\
1,418 \\
0,946 \\
0,631 \\
0,405 \\
0,212\end{array}$} & \multirow{9}{*}{$\begin{array}{r}0,9106 \\
0,5580 \\
0,3234 \\
0,1316 \\
-0,0441 \\
-0,2200 \\
-0,4125 \\
-0,6935\end{array}$} & 0,9206 & 658 & 694 \\
\hline & & & & 0,6029 & 678 & 692 \\
\hline & & & & 0,3471 & 670 & 686 \\
\hline & & & & 0,1363 & 665 & 684 \\
\hline & & & & $-0,0464$ & 665 & 682 \\
\hline & & & & $-0,2179$ & 664 & 686 \\
\hline & & & & $-0,3953$ & 660 & 689 \\
\hline & & & & $-0,6331$ & 644 & 690 \\
\hline & & & & $P_{\text {әкс п: }}=686$ & $\overline{P_{I}}=66$ & $I I=688$ \\
\hline
\end{tabular}

и 5, из которых видно, что экспериментально измеренная величина давления $\left(P_{\text {эксп. }}\right)$ ближе к той средней расчетной величине, в основу которой положены значения коэффициентов активности, определенные непосредственно из графика зависимости $\lg \frac{\gamma_{1}}{\gamma_{2}}$ эксп. $=f\left(x_{1}^{(1)}\right)$.

\section{ЛИ Т Е Р А Т У Р А}

1. Wichterle I., Hala E., Ind. Engng Chem. Fund., 2, 155 (1963).

2. Физико-химические свойства индивидуальных углеводородов, М., 1960.

3. С тэл л Д. Р., Таблицы давления паров индивидуальных веществ, М., 1949.

4. Краткий справочник химика, М., 1954.

5. Red lich O., K ister A. K., Ind. Engng Chem., 40, 345 (1948).

6. К удря вцев а Л., В и й т Х., Эй зен О., Изв. АНН ЭССР, Хим. Геол., 18,346 (1969).

7. К уд р я в и е в а Л., В и й т Х., Э й з ен О., Изв. АН ЭССР, Хим. Геол., 19, 22 (1970).

8. Ж аров В. Т., М о р а ч е в с к и й А. Г., Ж. прикл. химии, 36,2232 (1963).

9. Коган В. Б., Фридман В. М., Кафаров В. В., Равновесие между жидкостью и паром, М.-Л., 1966.

10. С ми рнов а Н. А., М о р а че в ски й А. Г., Ж. физ. химин, 34, 2546 (1960).

$\begin{array}{cc}\text { Институт химии } & \text { Поступила в редакцию } \\ \text { Академии наук Әстонской ССР } & 28 / \mathrm{X} 1969\end{array}$

HELLE VIIT, L. KUDRJAVTSEVA

VEDELIKU-AURU TASAKAAL BINAARSETES SUSTEEMIDES HEKSEEN-1-VESI,
HEKSEEN-1-ÄADIKHAPE JA HEPTEEN-1-VESI

Vedeliku-auru tasakaalulised koostised neis heterogeensetes süsteemides määrati isotermilistes tingimustes. Saadud andmete alusel arvutati tasakaalurōhud.

HELLE VIIT, L. KUDRJAWZEWA

\section{DAS DAMPF-FLUSSIGKEIT-GLEICHGEWICHT IN DEN SYSTEMEN HEXEN-1- WASSER, HEXEN-1-ESSIGSÄURE, HEPTEN-1-WASSER}

Es werden experimentelle Messwerte der isothermen Gleichgewichtszusammensetzung der Flüssigkeit und des Dampfes der genannten Systeme mit beschränkter gegenseitiger Löslichkeit mitgeteilt. Aus den ermittelten Daten werden Gleichgewichtstotaldrücke berechnet. 